\title{
Leber's hereditary optic neuropathy: heteroplasmy is likely to be significant in the expression of LHON in families with the 3460 ND1 mutation
}

\author{
G C M Black, K Morten, A Laborde, J Poulton
}

\begin{abstract}
Aim-To assess the effect of heteroplasmy on the expression of Leber's hereditary optic neuropathy (LHON) in a large family with the 3460 LHON mutation.

Methods-Mutation detection was performed by restriction enzyme digestion of polymerase chain reaction (PCR) products. Heteroplasmy was estimated by quantitation of wild type:mutant product ratios.

Results-There is a significant association between levels of mutant mtDNA and manifestation of the disease phenotype. Conclusion-As a high proportion of families with the 3460 mutation demonstrate heteroplasmy; this is likely to be a significant factor in disease expression. (Br f Ophthalmol 1996;80:915-917)
\end{abstract}

Leber's hereditary optic neuropathy (LHON) is an uncommon condition characterised in the late stage of the disease by bilateral optic atrophy, usually subacute in onset. In general, both eyes are involved sequentially, resulting in marked loss of central vision. The disease passes only through the maternal line and is associated with mitochondrial DNA (mtDNA) mutations, the most common of which are at positions $3460,{ }^{12} 11778,{ }^{3}$ and $14484 .{ }^{4}$ These mutations are estimated to account for $15 \%$, $50-70 \%$, and $10 \%$ of LHON pedigrees respectively.

Although the disease is caused by mtDNA mutations, many of the factors affecting the manifestation of the LHON phenotype remain unclear. In many cases wild type mtDNA is present as well as mutant (heteroplasmy). We have found a dosage effect of level of mutant on the phenotype.

Genetics Laboratory Department of Biochemistry, South Parks Road, Oxford G C M Black A Laborde

Department of Paediatrics, John Radcliffe Hospital, Headington, Oxford K Morten J Poulton

Correspondence to Dr J Poulton. minute), annealing $\left(55^{\circ} \mathrm{C}\right.$ for 1 minute), and elongation $\left(75^{\circ} \mathrm{C}\right.$ for 1 minute). The primers were designed to positions 3275-3295 (forward) and 3557-3577 (reverse) of the mtDNA, a product of 302 base pairs (bp) being amplified. The $3460 \mathrm{ND} 1 \mathrm{G} \rightarrow \mathrm{A}$ mutation, if present, removes a $\mathrm{BsaH} 1$ restriction enzyme site, which, when cleaved, produces fragments of 117 and $185 \mathrm{bp}$. Digestion with formed for 4 hours at $37^{\circ} \mathrm{C}$, using $45 \mu$ of the PCR reactant, $3 \mu \mathrm{l}$ NEBL4 $10 \mathrm{X}$ restriction enzyme buffer and $8 \mu \mathrm{l}$ water and this was then concentrated to $20 \mu \mathrm{l}$ by lyophilisation. The three fragments were resolved on a $2 \%$ agarose gel and stained with ethidium bromide and photographed (Fig 1). The negative was analysed by densitometry (Double beam microdensitometer, Loebl and $\mathrm{Co}$ ) to estimate the relative proportions of wild type to mutant mitochondria. Each individual was analysed on at least two separate occasions. It must be noted that ethidium bromide staining is not sensitive enough to detect the presence of faint bands and that individuals who appear homoplasmic may nevertheless be heteroplasmic at very low levels.

In such circumstances, heteroduplex formation, with one mutant and one wild type strand, will tend towards an overestimation of the fraction of mutant mitochondria, as such molecules will not be digested. ${ }^{7}$ In order to minimise such heteroduplex formation, all analyses were carried out using relatively few (29) cycles of PCR so that the Taq polymerase should still be effective at the end of the run. If not, as single stranded molecules would remain at the end of the final extension, they could reanneal as heteroduplexes. An analysis was carried out comparing the normal concentration of primers with double concentration (that is, $2 \mathrm{mM}$ instead of $1 \mathrm{mM}$ ) to ensure that these were not limiting towards the end of the cycle; this was shown to make no difference to the final estimations. Finally, an estimation was performed on three individuals adding $0.5 \mu \mathrm{l}$ 32P-dCTP (Amersham, Bucks) and $0.25 \mu$ Taq polymerase after the 28th cycle and then allowing the final cycle to run (data not shown). In this case, there was no denaturation-annealing step after primer extension in the presence of radioactive dCTP The comparison of the conventional estimation procedure with this estimation of the mutant:wild type products produced only in the final cycle suggests that heteroduplex formation does not substantially affect heteroplasmy estimations. $10 \mathrm{IU}$ BsaH 1 (New England Biolabs) was per-

\section{Results}

The family, L2, that was investigated has the 3460 mutation and is wild type at positions $4216,11778,13708,15257$, and $15812 .^{8}$ The analysis of heteroplasmy in family $\mathrm{L} 2$ is summarised in Figure 2. 

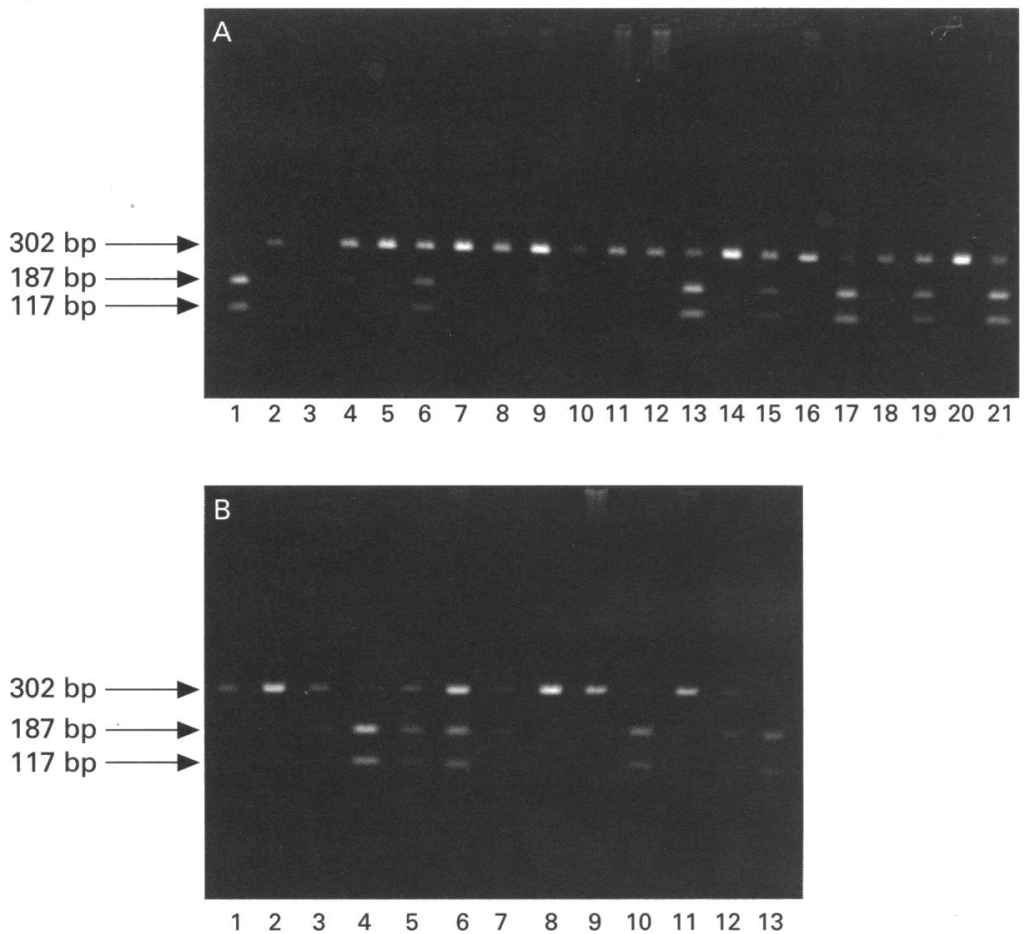

Figure 1 Polymerase chain reaction estimations of mitochondrial heteroplasmy in family L2. Heteroplasmy estimations, from densitometry, run on $2 \%$ agarose gel, then stained with ethidium bromide (\% mutant). (A) Lane 1, control 1 normal individual; lane 2, control 2 mutant control, known to be homoplasmic; lane 3, control 3 water; lane 4, IV-14 73\%; lane 5, IV-17 100\%; lane 6, IV-13 50\%; lane 7, IV-18 100\%; lane 8, IV-19 100\%; lane 9, IV-20 100\%; lane 10, III-9 100\%; lane 11, IV-3 100\%; lane 12 III-9 100\%; lane 13, III-7 20\%; lane 14, III-6 100\%; lane 15, IV-8 49\%; lane 16, V-1 100\%; lane 17, IV-16 13\%; lane 18, V-2 100\%; lane 19, III-5 41\%; lane 20, IV-3 100\%; lane 21, III-2 $19 \%$. (B) Lane 1, V-1 100\%;lane 2, V-2 100\%;lane 3, IV-14 62\%; lane 4, IV-16 14\%; lane 5, IV-13 40\%; lane 6, IV-10 50\%; lane 7, IV-8 48\%; lane 8, IV-1 100\%; lane 9, III-9 100\%; lane 10, III-7 15\%; lane 11 III-6 100\%; lane 12, III-5 40\%; lane 13 III-2 $16 \%$.

Assessment of the levels of mutant:wild type suggest that this is likely to be relevant to the expression of the disease. A high proportion of affected individuals have levels of mutant mtDNA above $50 \%$. Figure 3 shows the distribution of disease status for different mutation levels (at or above $25 \%, 50 \%$, and $75 \%$ respectively) for the 36 individuals tested, of any age, who were related to the maternal line. The analysis has been restricted to broad categories

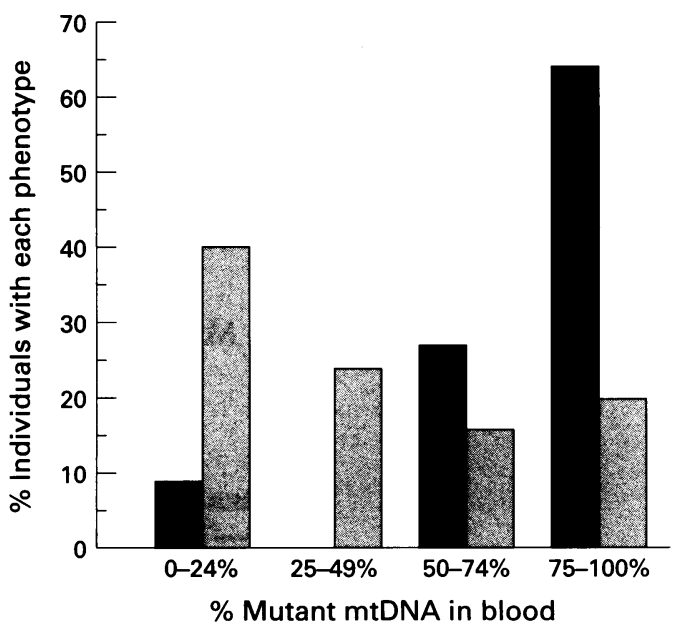

Figure 3 Comparison of level of mutant $m t D N A$, in blood, in affected (solid bars) and unaffected (shaded bars) individuals.

in order to exclude error as a result of heteroduplex formation during heteroplasmy estimations.

\section{Discussion}

The aetiology of LHON is complex. The disease shows considerable heterogeneity at both phenotypic and genotypic levels and the relation between the two remains poorly understood.

The analysis of heteroplasmy in family L2 shows that for the 3460 mutation, as for the $11778,{ }^{9}$ the level of mtDNA mutation appears to affect the phenotype of an individual. This was assayed in peripheral tissues, and in other mitochondrial diseases such an analysis does not necessarily give an accurate indication of the mutant:wild type status in an affected tissue. There may be wide variation in the mitochondrial populations of different tissues: in Kearnes-Sayre syndrome, for example, mtDNA deletions are readily detectable in muscle but not in blood. ${ }^{10}$ Therefore, inferences made from data on heteroplasmy in

I

III
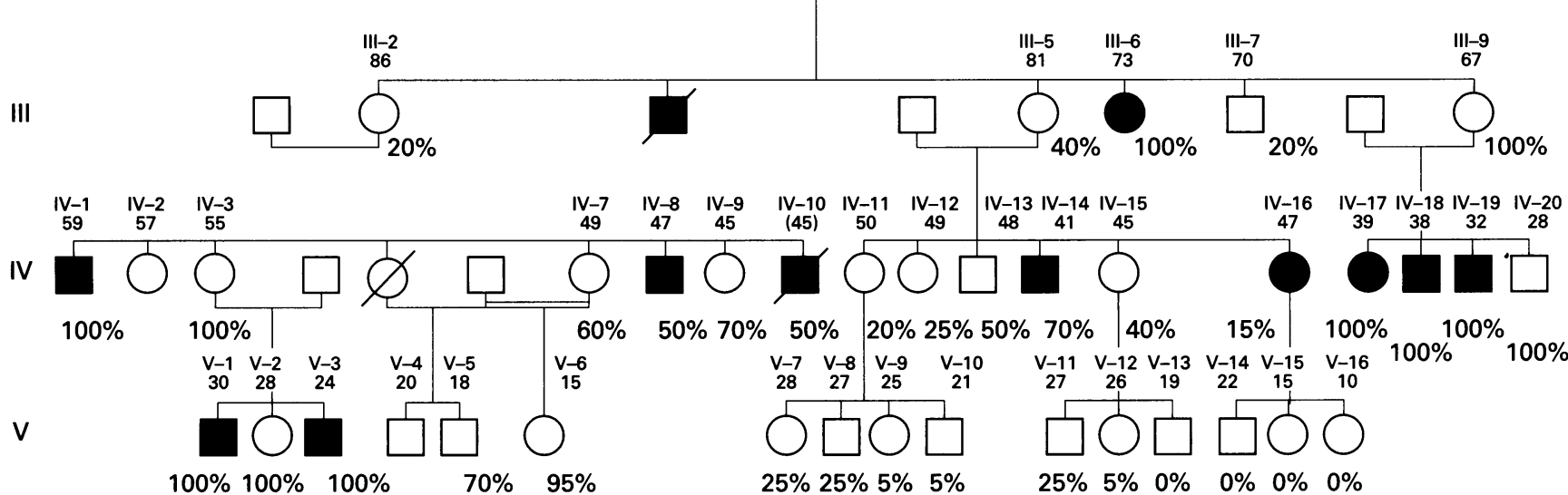

Figure 2 Analysis of heteroplasmy in L2 pedigree. (Age of individuals and percentage of mutant mitochondria both indicated.) 
white cells must be treated with caution, in particular when making statements about prognosis or probabilities of passing on the disorder.

The hypothesis that the phenotype of an individual in this family is dependent on the level of mutation was then tested by means of a $\chi^{2}$ test (Fisher's exact tests), applied to both sexes together. As such an analysis may be biased by including young, unaffected individuals who may be expected to manifest the disease later in life, the test was then repeated to include only those unaffected individuals over 45 years of age. There is a strong correlation between high levels of mutant $(\geq 50 \%, p=$ 0.0026 and $\geq 75 \%, p=0.014)$ and the disease phenotype and this holds both for those of all ages and, more significantly, when looking only at those unaffected individuals over 45 years ( $\geq 50 \%, p=0.029$ and $\geq 75 \%, p=0.036$ ). There is no significant correlation for low levels of mutant $(25 \%)$.

It is notable, however, that female IV-16, is affected despite very low mutant levels (15\%). Such correlations are obviously not absolute and would not, therefore, be sufficient for counselling purposes. Contrary to what has been suggested elsewhere, ${ }^{9}$ there does not appear to be a close correlation between the level of heteroplasmy and the probability of passing on the disease: five out of the 10 affected individuals in generations IV and V have inherited the disease from females III-2 and III-5 who both have relatively low observed levels of mutant mitochondria.

As has been described by others, ${ }^{11}$ the level of heteroplasmy shows a considerable move towards fixation with the passing of generations. Within individuals of generation $\mathrm{V}, 10$ out of 13 are homoplasmic for either wild type or mutant, compared with $2 / 5$ in generation III and $6 / 16$ in generation IV. There is no evidence for selection of either the mutant or the wild type mtDNA.

Investigations of other families suggest that a large number of 3460 carrying families are heteroplasmic; 9/19 tested among 35 families were shown to be heteroplasmic. ${ }^{8}$ If this is the case, then either there is no drift towards fixation for this mutation (a hypothesis which this family does not appear to support) or a large proportion of families with the 3460 mutation are the result of a recent mutation.

This family demonstrates a significant correlation between high levels of mutant mtDNA and manifestation of LHON among heteroplasmic patients. It is likely that this is a significant factor in the expression of the disease phenotype.

JP and KM were supported by The Wellcome Trust. We would like to thank Joan BronteSmith for help in collecting family data, and Professor I Craig, Dr G K Brown, and Professor E R Moxon for their help and encouragement.

1 Huoponen K, Vilkki, J, Aula, P, Nikoskelainen, EK, Savontaus M-L. A new mtDNA mutation associated with Leber hereditary optic neuroretinopathy. Am $\mathcal{F}$ Hum Genet 1991;48:1147-53

2 Howell N, Bindoff LA, McCullough DA, Kubacka I, Poulton J, Mackey D, et al. Leber hereditary optic neuropathy: identification of the same mitochondrial ND1 mutation in six pedigrees. Am $₹$ Hum Genet 1991;49:939-50.

3 Wallace DC, Singh G, Lott MT, Hodge JA, Schurr TG Wallace DC, Singh G, Lott MT, Hodge JA, Schurr TG, with Leber's hereditary optic neuropathy. Science 1988;242: with Leber's

4 Mackey D, Howell N. A variant of Leber hereditary optic neuropathy characterized by recovery of vision and by an unusual mitochondrial genetic etiology. Am $₹$ Hum Genet 1992;51:1218-28.

5 Howell N, Halvorson S, Burns J, McCullough DA, Poulton, $\mathrm{J}$. When does bilateral optic atrophy become Leber hereditary optic neuropathy? Am f Hum Genet 1993;53:959-63.

6 Poulton J, Deadman ME, Bronte-Stewart J, Foulds WS Poulton J, Deadman ME, Bronte-Stewart J, Foulds WS, Gardiner RM. Analysis of mitochondrial DNA in Leber's

7 Larsson N, Tulinius M, Holme E, Oldfors A, Anderson O, Wahlstrom J, Aasly J. Segregation and manifestations of the mtDNA $t R N A^{\text {lys }} A \rightarrow \mathrm{G}^{(834)}$ mutation of myoclonus epilepsy and ragged red fibres (MERRF) syndrome. $A m \mathcal{F}$ Hum Genet 1992;51:1201-12.

8 Black G, Craig I, Oostra R, Norby S, Rosenberg T, Morten $\mathrm{K}$, et al. Leber's hereditary optic neuropathy: implications of the sex ratio for linkage studies in families with the 3460 ND1 mutation. Eye 1995;9:513-6.

9 Holt IJ, Miller DH, Harding AE. Genetic heterogeneity and mitochondrial DNA heteroplasmy in Leber's hereditary optic neuropathy. $\mathcal{F}$ Med Genet 1989;26:739-43.

10 Larsson NG, Holme E, Kristiansson B, Oldfors A, Tulinius $M$. Progressive increase of the mutated mitochondrial DNA fraction in Kearns-Sayre syndrome. Paediatr Res 1990;28:131-6.

11 Villki J, Savontaus M-L, Nikoskelainen EK. Segregation of mitochondrial genomes in a heteroplasmic lineage with Leber hereditary optic neuroretinopathy. Am $\mathcal{f}$ Hum Genet 1990;47:95-100. 